\title{
The Mössbauer Spectroscopy Studies of Cementite Precipitations during Continuous Heating from As-Quenched State of High Carbon Cr-Mn-Mo Steel
}

\author{
J. KraWCZYK ${ }^{a, *}$, P. BAŁA ${ }^{a}$ AND A. $\mathrm{HANC}^{b}$ \\ ${ }^{a}$ AGH University of Science and Technology \\ Faculty of Metals Engineering and Industrial Computer Science \\ al. Mickiewicza 30, PL-30-059 Kraków, Poland \\ ${ }^{b}$ Institute of Materials Science, Silesian University \\ Bankowa 12, 40-007 Katowice, Poland
}

This work complements the knowledge concerning the kinetics of cementite precipitation during tempering. Investigations were performed on $120 \mathrm{MnCrMoV} 8-6-4-2$ steel. The samples of investigated steel were austenitized at the temperature of $900^{\circ} \mathrm{C}$ and quenched in oil. Then four of five samples were tempered. Tempering consisted of heating the samples up to chosen temperatures at the heating rate of $0.05^{\circ} \mathrm{C} / \mathrm{s}$ and fast cooling after reaching desired temperature. This work presents the results of investigations performed carried out using the Mössbauer spectroscopy technique and their interpretation concerning cementite nucleation and growth during tempering. The values of hyperfine magnetic field on ${ }^{57} \mathrm{Fe}$ atomic nuclei, determined for the third component of the Mössbauer spectrum as regards to its intensity, indicate that these are the components coming from ferromagnetic carbides. Big differences in hyperfine magnetic fields coming from Fe atoms existing in the structure of carbides, measured on samples heated up to the temperatures of $80^{\circ} \mathrm{C}$ and $210^{\circ} \mathrm{C}$, in comparison with values for ${ }^{57} \mathrm{Fe}$ atoms precipitated from carbides during heating up to the temperature of $350^{\circ} \mathrm{C}$ and $470^{\circ} \mathrm{C}$, allow to state that these are the carbides of different crystal structure. The influence of hardened steel heating temperature on cementite precipitation was determined. The Mössbauer spectroscopy was applied not only for magnetic hyperfine fileld studies, but also to analyze the values of quadrupole splitting and isomeric shift, which resulted in significant conclusions concerning the changes in cementite precipitations morphology, chemical composition and the level of stresses being present in this research.

PACS numbers: 76.80.+y, 31.30.Gs, 75.50.Bb

*corresponding author; e-mail: jkrawczy@ruczaj.pl; jkrawczy@metal.agh.edu.pl 


\section{Introduction}

The application of dilatometric, magnetic, X-ray, and microscopic analysis gives a lot of useful information about the kinetics of precipitation of cementite during tempering [1-8]. Many works [9-17] showed that the Mössbauer spectroscopy gives a possibility to achieve new information which may help to facilitate more detailed interpretation of the phenomena connected with transformations on-going during tempering of hardened steel. In such cases, the Mössbauer spectroscopy can help to confirm whether cementite precipitations are present in the microstructure of steel. The Mössbauer spectroscopy allows to obtain information on nucleation mechanism of cementite precipitates and also on mechanism of their growth during heating of the hardened steel. This information comes from a significantly larger area than in the case of transmission electron microscopy (TEM) investigations. It makes possible to eliminate the randomness of observation site selection, characteristic of TEM (information comes from very small areas).

This work presents the results of investigations using the Mössbauer spectroscopy technique and their interpretation concerning cementite precipitations in relation to previously conducted dilatometric and microscopic investigations $[1,18]$. The aim of this work is to determine the cementite precipitation occurring during continuous heating after quenching of a high carbon alloy steel and its effect on the development of steel microstructure.

\section{Test material}

Investigations were performed on 120MnCrMoV8-6-4-2 steel, which was designed in 1998, in Phase Transformations Research Group of Department of Physical and Powder Metallurgy at the Faculty of Metals Engineering and Industrial Computer Science at AGH University of Science and Technology in Kraków. Table lists the chemical composition of the tested steel.

\section{TABLE}

The chemical composition of the investigated steel [mass \%].

\begin{tabular}{c|c|c|c|c|c|c|c|c}
\hline \hline $\mathrm{C}$ & $\mathrm{Mn}$ & $\mathrm{Si}$ & $\mathrm{P}$ & $\mathrm{S}$ & $\mathrm{Cr}$ & $\mathrm{Mo}$ & $\mathrm{V}$ & $\mathrm{Al}$ \\
\hline 1.22 & 1.93 & 0.19 & 0.018 & 0.02 & 1.52 & 0.36 & 0.17 & 0.04
\end{tabular}

\section{Experimental details}

Samples, taken from the investigated steel, were austenitized at the temperature of $900^{\circ} \mathrm{C}$ and quenched in oil. Austenitizing time was $20 \mathrm{~min}$. Then four of five samples were tempered. Tempering consisted of heating the samples up to chosen temperatures at the heating rate of $0.05^{\circ} \mathrm{C} / \mathrm{s}$ and fast cooling after reaching the desired temperature. 
Sample No. 1 was left in as-quenched state. After quenching, sample No. 2 was heated up to $80^{\circ} \mathrm{C}$, sample No. 3 was heated up to $210^{\circ} \mathrm{C}$, sample No. 4 was heated up to $350^{\circ} \mathrm{C}$ and sample No. 5 was heated up to $470^{\circ} \mathrm{C}$. The temperatures up to which the investigated samples were heated had been selected in order to enable the precipitation of $\varepsilon$ carbide in sample No. 2 during tempering. Sample No. 3 was heated up to the temperature at which the precipitation of $\varepsilon$ carbide was completed and cementite started to precipitate without starting a transformation of retained austenite. The temperature up to which the sample No. 4 was heated after quenching had been selected as a temperature corresponding to the completion of transformation of retained austenite. Sample No. 5 was heated up to the temperature at which the precipitation of cementite was completed. All the temperatures mentioned above were selected basing on continuous heating transformations (CHT) from as-quenched state diagram published in work [1].

For the study, a conversion electron Mössbauer spectroscopy (CEMS) with gas detector, filled with $98 \% \mathrm{He}+2 \% \mathrm{Ar}$, under pressure of $0.9 \mathrm{~atm}$. was applied. A Mössbauer source consisted of ${ }^{57} \mathrm{CoRh}$ of activity of $10 \mathrm{mCi}$. Application of CEMS technique allowed to investigate the surface layers of thickness of about $100 \mathrm{~nm}$. In the case of sample No. 4 two sides were investigated, one was grinded only, while the other one was polished after grinding. For other samples, the Mössbauer spectra were recorded from polished surfaces.

\section{Results and discussion}

Analysis of the intensity of individual component spectra may be used for determination of the amount of phase constituents, and for the study of qualitative changes of the quantity of particular phase constituents during steel tempering especially.

Basing on the analysis of hyperfine magnetic field and on investigations carried out earlier $[1,18]$ using various techniques, it is possible to determine which phase a particular spectrum comes from. The analysis of hyperfine magnetic field (the Zeeman sextets) allowed to distinguish between component spectra coming from ${ }^{57} \mathrm{Fe}$ atoms existing in the structure of martensite (or ferrite in the case of higher tempering temperatures), the ones in the structure of $\varepsilon$ carbide, and in cementite (Fig. 1), independently precipitated during tempering. A component spectrum was also identified, characterized by single peak (without quadrupole or Zeeman splitting) as corresponding to precipitations of alloyed hypereutectoid cementite (which is paramagnetic), undissolved during austenitizing.

The obtained Mössbauer spectra were presented in Fig. 2. A component of secondary cementite precipitating from the matrix was marked when present.

Large differences in the values of hyperfine magnetic fields from ${ }^{57} \mathrm{Fe}$ atoms located in carbides structure, measured in the sample tempered to $210^{\circ} \mathrm{C}$ $267 \mathrm{kGs}$ - in comparison to analogous values coming from ${ }^{57} \mathrm{Fe}$ atoms in structure of carbides precipitated during tempering to 350 and $470^{\circ} \mathrm{C}$ (175 and $171 \mathrm{kGs}$, respectively) enable to ascertain that these carbides have various crystal structures. 


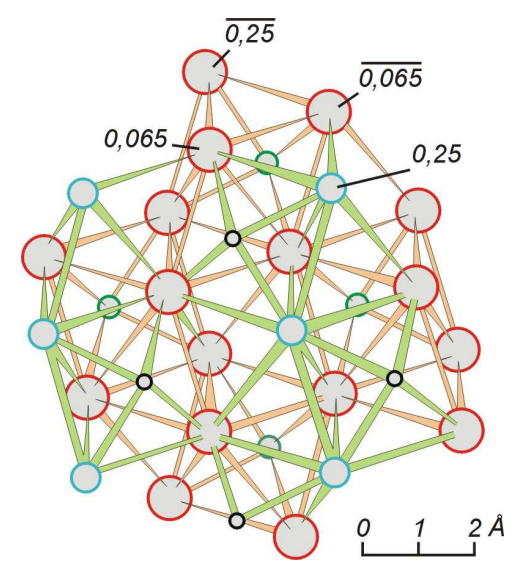

Fig. 1. Crystal structure of cementite according to Jack [19].

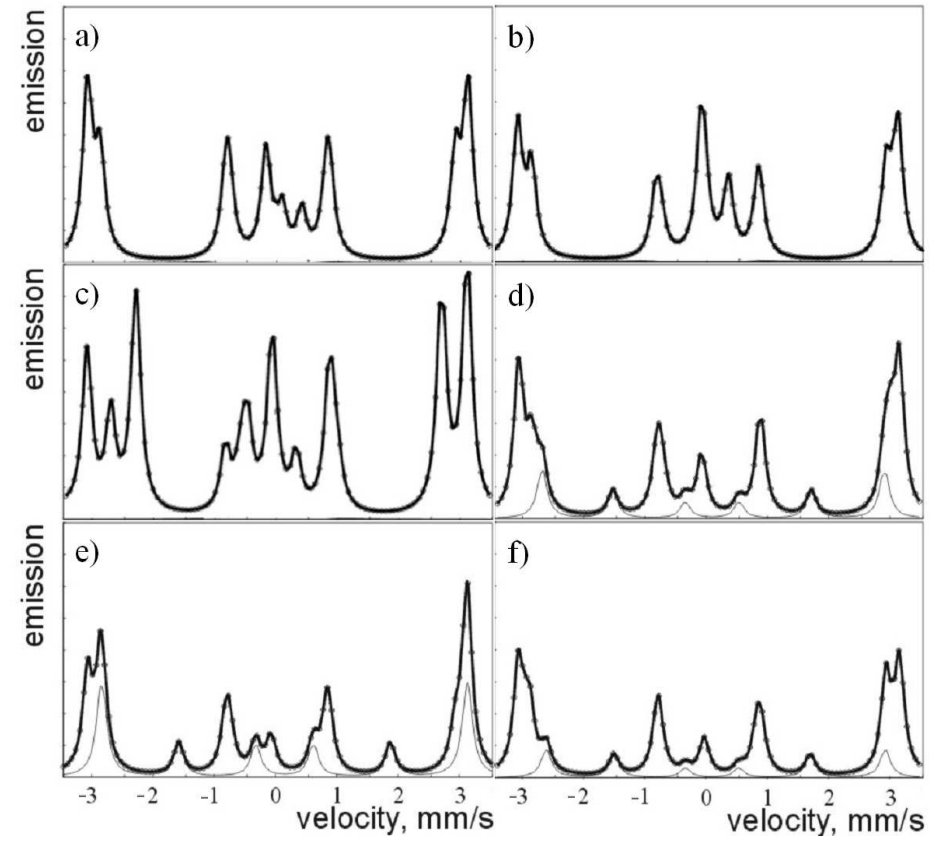

Fig. 2. Mössbauer spectra with marked components of cementite precipitating while tempering: (a) after hardening — polished surface, (b) after tempering up to $80^{\circ} \mathrm{C}-$ polished surface, (c) after tempering up to $210^{\circ} \mathrm{C}$ - polished surface, (d) after tempering up to $350^{\circ} \mathrm{C}$ - polished surface, (e) after tempering up to $350^{\circ} \mathrm{C}$ - grinded surface, (f) after tempering up to $470^{\circ} \mathrm{C}$ - polished surface.

Literature data [12] and investigations of phase-transition products forming during tempering this steel, carried out using other methods $[1,18]$, indicate that the component spectrum originating from carbides, measured in the sample tempered 
to $210^{\circ} \mathrm{C}$, comes from $\varepsilon$ carbides $\left(\mathrm{Fe}_{2.4} \mathrm{C}\right)$, whereas component spectra obtained from samples tempered to 350 and $470^{\circ} \mathrm{C}$ originate from ${ }^{57} \mathrm{Fe}$ atoms located in cementite structure. Field values lower than the ones reported in the literature for cementite [12] indicate that this cementite is alloyed to some extent. Besides, in the case of the sample tempered to $350^{\circ} \mathrm{C}$, the value of hyperfine magnetic field, occurring in the area of ${ }^{57} \mathrm{Fe}$ nuclei located in the cementite structure is higher in the case of component spectrum obtained for grinded-only surface (184 kGs) than in the case of spectrum recorded for a surface polished after grinding. It may result from hardness of the carbide phase higher than the one of the matrix. It is also the cause of the fact that in the case of polished surface of the sample tempered to $350^{\circ} \mathrm{C}$, a higher share of cementite $(22 \%)$ was ascertained than in the case of grinded surface $(13 \%)$. The latter value seems more credible to the authors. The observed decrease (to 10\%) in share of the component spectrum originating from the cementite after tempering the sample to $470^{\circ} \mathrm{C}$ may be connected with the fact that temperature of $350^{\circ} \mathrm{C}$ corresponds to completion of retained austenite's transformation. Higher tempering leads to equalization of chemical composition of the matrix. This results in a change of thermodynamic equilibrium between precipitated carbides and the matrix. In new thermodynamic conditions, the state of equilibrium may occur for a lower share of cementite or the share of Fe atoms in the cementite may be changed. Therefore its partial dissolution in the matrix occurs. Moreover, at higher temperature solubility of carbon in ferrite (which constitutes the matrix in the case) slightly increases. This is accompanied by processes of spheroidization and coagulation, which require dissolution of part of the cementite before its repeated precipitation.

Quadrupole effects QS on ${ }^{57} \mathrm{Fe}$ nuclei located in the structure of the cementite precipitated during tempering are small — for the polished samples they amounted to $0.03 \mathrm{~mm} / \mathrm{s}$ only, and on polished surface they were not found. It allows to ascertain that a slight asymmetry of location of such atoms in the crystal structure is mainly connected with interphase boundaries.

The values of isomeric shifts (IS) for the component spectra originating from cementite precipitations do not vary significantly, and they amount to $0.08 \mathrm{~mm} / \mathrm{s}$ for polished surfaces of the sample tempered to $350^{\circ} \mathrm{C}$, and to $0.09 \mathrm{~mm} / \mathrm{s}$ in the case of the sample tempered to $470^{\circ} \mathrm{C}$. A higher value of the isomeric shift was ascertained for grinded surface of the sample tempered to $350^{\circ} \mathrm{C}$. It amounted to $0.11 \mathrm{~mm} / \mathrm{s}$. The difference may result from a slight increase in stress level in near-surface zone of the grinded sample and of the polished one.

An increase in $A 2$ value for ${ }^{57} \mathrm{Fe}$ atoms located in the cementite structure was found (from 1.5 to 2.3). It results from an increase in heating temperature of the hardened sample, from 350 to $470^{\circ} \mathrm{C}$. One may connect it with directional cementite growth (depending on crystallographic orientation of the matrix). It results from the fact that cementite nucleates on boundaries of the strips or grains, without exhibiting a strong dependence on the crystallographic orientation of the 


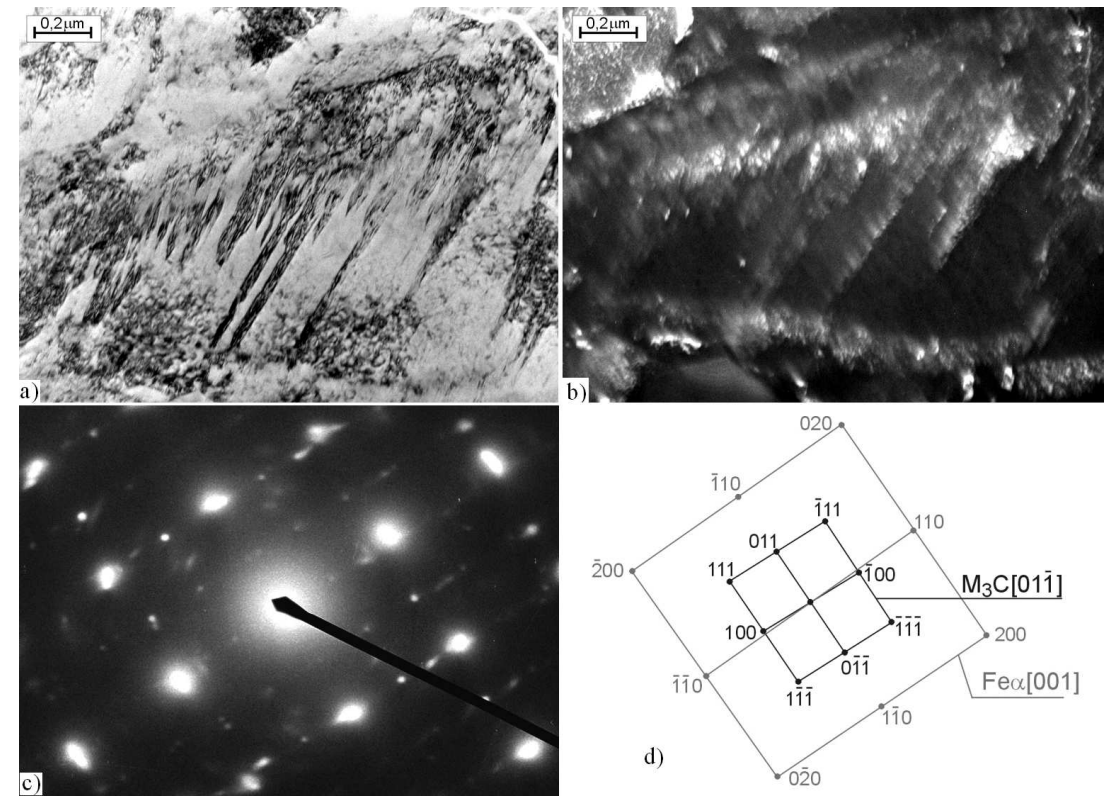

Fig. 3. Cementite precipitations in investigated steel (TEM) quenched from $900^{\circ} \mathrm{C}$ and subsequently heated to $370^{\circ} \mathrm{C}$ with a heating rate of $0.05^{\circ} \mathrm{C} / \mathrm{s}$ : (a) bright field, (b) dark field - from (111) $\mathrm{M}_{3} \mathrm{C}$ reflection, (c) diffraction pattern for the area visible on part (a), and (d) solution of a diffraction pattern for part (c) [1].

matrix. Only its growth depends on the orientation, which leads to texturing adequate to it. Such a mechanism of growth of the cementite precipitations during tempering is confirmed by electron microscopy (Fig. 3). This proves independent nucleation of cementite during tempering of the investigated steel.

\section{Conclusions}

The obtained results lead to the following conclusions:

1. The Mössbauer spectroscopy enables allows to investigate transformations of transition carbides during tempering of the investigated steel.

2. During heating of the quenched steel, cementite nucleates independently of $\mathrm{Fe}_{2.4} \mathrm{C}$ carbides.

3. Growth of the cementite precipitations depends on the crystallographic orientation of the matrix.

4. Cementite precipitating in the investigated steel during tempering is enriched with alloying elements.

5. Partial secondary dissolution of cementite in the ferritic matrix after completion of the cementite's precipitation has been found. 


\section{Acknowledgments}

The authors thank Prof. J. Fra̧ckowiak for help in this study. The work was supported by the State Committee for Scientific Research, grant no. PB$581 / \mathrm{T} / 2006$.

\section{References}

[1] P. Bała, J. Pacyna, J. Krawczyk, Archiv. Metall. Mater. 52, 113 (2007).

[2] P. Bała, J. Pacyna, J. Krawczyk, Archiv. Mater. Sci. Eng. 28, 517 (2007).

[3] P. Bała, J. Pacyna, J. Krawczyk, J. Achiev. Mater. Manufact. Eng. 20, 79 (2007).

[4] J. Krawczyk, P. Bała, J. Pacyna, J. Achiev. Mater. Manufact. Eng. 21, 59 (2007).

[5] P. Bała, J. Pacyna, J. Krawczyk, J. Achiev. Mater. Manufact. Eng. 19, 19 (2006).

[6] P. Bała, J. Pacyna, J. Krawczyk, J. Achiev. Mater. Manufact. Eng. 18, 47 (2006).

[7] P. Bała, J. Pacyna, J. Krawczyk, J. Achiev. Mater. Manufact. Eng. 22, 15 (2007).

[8] P. Bała, J. Pacyna, J. Krawczyk, Archiv. Mater. Sci. Eng. 28, 98 (2007).

[9] S.-J. Kown, S.J. Oh, J.H. Kim, S. Kim, S. Lee, Scr. Mater. 40, 131 (1999).

[10] V.G. Gavriljuk, Mater. Sci. Eng. A 345, 81 (2003).

[11] R. Ilola, V. Nadutov, M. Valo, H. Hänninen, J. Nucl. Mater. 302, 185 (2002).

[12] V.A. Shabashov, L.G. Korshunov, A.G. Mukoseev, V.V. Sagaradze, A.V. Makarov, V.P. Pilyugin, S.I. Novikov, N.F. Vildanova, Mater. Sci. Eng. A 346, 196 (2003).

[13] V.A. Shabashov, A.G. Mukoseev, V.V. Sagaradze, Mater. Sci. Eng. A 307, 91 (2001).

[14] A.G. Balanyuk, V.G. Gavriljuk, V.N. Shivanyuk, A.I. Tyshchenko, J.C. Rawers, Acta Mater. 48, 3813 (2000).

[15] E.J. Miola, S.D. De Souza, M. Olzon-Dionysio, D. Spinelli, C.A. Dos Santos, Surf. Coat. Technol. 116-119, 347 (1999).

[16] P. Budziński, P. Tarkowski, E. Jartych, A.P. Kobzev, Vacuum 63, 737 (2001).

[17] Y. Jirásková, J. Svoboda, O. Schneeweiss, W. Daves, F.D. Fischer, Appl. Surf. Sci. 239, 132 (2005).

[18] P. Bała, Ph.D. Thesis, AGH University of Science and Technology, Kraków 2007, p. 42.

[19] H.K. Jack, J. Iron Steel Institute 169, 26 (1959). 